\title{
Comparing Clinicopathologic Features and Surgical Treatment of Premenopausal Breast Cancer across Italy and China: Report from a Medical Exchange Program
}

\author{
Alessandro Fancellu ${ }^{a}$ Xue Yun Zhao $^{b}$ Pietrina Cottu ${ }^{a}$ Valeria Sanna ${ }^{c}$ \\ Yuan Ping Li ${ }^{b}$ Qin Zhu ${ }^{b}$ Cinzia Tanda ${ }^{a}$ Ying Yi Zhang ${ }^{b}$ Yan Mei Lai ${ }^{b}$ \\ Giorgio Carlo Ginesu ${ }^{a}$ Shu Qin Dai ${ }^{b}$ Alberto Porcu ${ }^{a}$ \\ a Unit of General Surgery 2-Clinica Chirurgica, Department of Medical, Surgical and Experimental Sciences, \\ University of Sassari, Sassari, Italy; ${ }^{b}$ Department of Thyroid and Breast Surgery, People's Hospital of Leshan, \\ Leshan, China; ' Division of Medical Oncology, AOU Sassari, Sassari, Italy
}

\section{Keywords}

Breast cancer · Premenopause · Italy · China · Surgical oncology

\begin{abstract}
Background: This study investigated the differences in clinicopathologic features and surgical treatment between an Italian and $\mathrm{a}$ Chinese cohort of premenopausal women with breast cancer, and highlighted the potential advantages of international medical exchange projects. Methods: Premenopausal women who underwent surgical treatment between 2012 and 2016 at one Italian and one Chinese institution participating in a medical exchange program were compared. Factors associated with the probability to receive mastectomy were determined via logistic analysis. Changes in surgical management at the Chinese institution in the period 2018-2019, after the exchange program, were also evaluated. Results: A total of 505 patients, 318 from Italy and 187 from China, were evaluated. The Chinese patients had more frequently advanced-stage tumours, large tumour size (30.9 vs. $18.1 \mathrm{~mm}, p<0.01$ ), invasive carcinoma ( 92.5 vs. $83.3 \%$, $p<0.01$ ), positive axillary lymph nodes (54.5 vs. $27.4 \%, p<$ 0.01 ), Her-2 positivity ( 36.4 vs. $22.0 \%, p<0.01$ ), and high proliferative index ( 55.1 vs. $30.2 \%, p<0.01$ ). Positive oestrogen receptor status and rates of triple-negative breast cancer did
\end{abstract}

not differ (77.0 vs. $69.5 \%, p=0.09$ and 14.2 vs. $16 \%, p=0.56$, respectively). Mastectomy rates were higher among Chinese women ( 85 vs. $41 \%, p<0.001$ ), whereas use of sentinel node biopsy was more frequent among Italian women (77 vs. 33\%, $p<0.001)$. Chinese women had more than 4 -fold higher risk of receiving mastectomy. In the last 2 years, the rates of breast-conserving surgery and sentinel node biopsy at the Chinese institution increased from 15 to $23 \%$, and from 33 to $42 \%$, respectively. Conclusions: Tumour features and surgical strategies for premenopausal breast cancer may differ significantly between Italy and China. Since the international exchange program, patients from the Chinese institution have been offered more frequently less invasive surgery. International exchange programs can help in designing epidemiological studies which may be useful for strategies to improve breast cancer management and control.

(c) 2020 S. Karger AG, Basel

\section{Introduction}

Breast cancer represents a major public health issue in all continents. However, significant diversity exists regarding tumour characteristics, diagnostic work-up, and treatment modalities between countries worldwide [1-4]. The reasons behind these findings are various and com- 
plex and include diversity in tumour genetics, cultural and demographic variables, as well as differences in health policies $[3,5,6]$. Although the incidence rates of breast cancer in Asia are lower than in western countries, they have been increasing recently $[3,7-9]$. The rapid increase in the incidence of the disease is a reason for concern in China, especially in urban areas [10]. The speedy development of China's economy probably played an important role, since more and more people have moved from rural areas to large cities, where cancer rates are higher. In China, the estimated overall crude incidence rate of breast cancer is 32.43 per 100,000 , accounting for $16.2 \%$ of all cases of cancer in women [11]. In Italy, the estimated overall crude incidence rate is about 120 per 100,000, accounting for $29 \%$ of all cases of cancer in women [12]. Recent research studies have reported an increase of breast cancer incidence in premenopausal women in several Asian countries, including China [2, 5-11, 13]. In general, the age of onset is younger in China compared with Western countries $[2,13]$. In a retrospective study including 4,211 Chinese breast cancer patients, age at diagnosis was reported to be 48 years, which is noticeably younger than that observed in Western counterparts [8]. Feng et al. [9] reported that almost $60 \%$ of cases in Chinese women are diagnosed before the age of 50 years.

A medical exchange program denominated "Specialist International Clinical Training" has been launched at the University of Sassari in 2015. To date, more than 450 Chinese clinicians have been trained at the University Hospitals. All participants were engaged in a highly specialized training course lasting 3 months to hone their expertise in the management and performance of clinical activities. Field-specific activities were also organized based on the specific profiles of trainees. Relationships among physicians have brought information and ideas to share for comparative studies.

While several studies have been published comparing breast cancer epidemiology and management between China and the USA [1, 14], comparative studies between China and European countries in this field are scarce. In this study, drawing on the aforementioned program, we sought to compare an Italian and a Chinese cohort of premenopausal women with breast cancer in order to assess the main differences regarding both clinicopathologic features and surgical treatment. The potential benefits of medical exchange programs in promoting health service improvement were also addressed.

\section{Methods}

In 2017, a group of breast surgeons from the People's Hospital of LeShan, (province of SiChuan, China) joined the Breast Team of the Unit of General Surgery 2 of the Department of Medical, Surgical and Experimental Sciences of the University of Sassari.
The latter institution is the referral centre for breast cancer treatment in Northern Sardinia, and satisfies the requirements of a specialist breast centre as identified by EUSOMA [15]. Breast surgeons from the 2 institutions have kept in touch, continue to exchange information about patient management, and discuss clinical cases.

We performed a retrospective analysis by using institutionalapproved, prospectively maintained databases from the 2 institutions. For the purposes of this study, we queried our databases for any premenopausal patients with breast cancer undergoing surgery between surgery between 2012 and 2016. Patients were excluded from the study if they presented with metastatic disease (stage IV) or refused surgery, or underwent surgery for breast cancer recurrence. Patients who had preoperative chemotherapy (all of whom belonged to the Italian institution) were included in the study. At both institutions, preoperative work-up included either total body CT scan or liver ultrasound and chest X-ray. Bone scintigraphy was carried out in selected cases.

The collected data included patients' age, tumour size, histotype, tumour grade, oestrogen and progesterone receptor status, proliferative index (Mib-1), Her-2 status, sentinel node biopsy, axillary lymph nodes status, type of surgery (breast conservation or mastectomy), and postoperative adjuvant treatments (chemotherapy, endocrine therapy, radiotherapy). We also evaluated the changes in surgical management of breast cancer in the Chinese institution after the exchange period, when the Chinese surgeons returned to their country (2018-2019).

\section{Statistical Analysis}

The patients' demographic and tumour characteristics were summarized with descriptive statistics. Continuous variables were evaluated as means \pm SDs and compared using the $t$ test. Differences in proportions between the groups were evaluated using the $\chi^{2}$ test. All $p$ values lower than 0.05 were considered to indicate statistical significance. The likelihood of receiving mastectomy was analysed through a multivariable logistic regression model. Covariates were chosen based on clinical significance, and they were dichotomized to a binary variable (country Italy vs. China; age $\leq 40$ vs. $>40$ years; histotype invasive vs. in situ; tumour size $\leq 2$ vs. $>2$ $\mathrm{cm}$; lymph node status positive vs. negative). For each variable, a reference category was chosen, generally the no-exposure or majority category and the other category was compared with the reference one. The OR in each category versus the odds in the reference category were estimated. Kaplan-Meier curves and log-rank test were used to compare overall survival and disease-free survival. Statistical analyses were conducted by using SPSS Statistics 20 (IBM Corporation, Armonk, NY, USA).

\section{Results}

\section{Demographic and Clinicopathologic Characteristics}

Overall, 505 patients operated on during the period 2012-2016 (318 from Italy and 187 from China) were included in the analysis. Demographic and clinicopathologic characteristics are summarized in Table 1 . The mean age was similar between the two cohorts ( 44.5 vs. 43.7 years, $p=0.10$ ). Overall, $78 \%$ of patients were aged over 40 years (76.4\% in the Italian cohort and $81.3 \%$ in the Chinese cohort, $p=0.20$ ). Mean tumour size was smaller in the Italian patients ( 18.1 vs. $30.9 \mathrm{~mm}, p<0.001)$. Tumour size distri- 
Table 1. Demographic and clinicopathologic characteristics of the study populations

\begin{tabular}{|c|c|c|c|c|}
\hline Characteristic & Total $(n=505)$ & Italy $(n=318)$ & China $(n=187)$ & $p$ value \\
\hline Age, years & $44.2 \pm 5.3(18-53)$ & $44.5 \pm 5.5(18-53)$ & $43.7 \pm 5.1(23-51)$ & 0.10 \\
\hline Age group distribution & & & & 0.20 \\
\hline$\leq 40$ years & $110(21.8)$ & $75(23.6)$ & $35(18.7)$ & \\
\hline$>40$ years & $395(78.2)$ & $243(76.4)$ & $152(81.3)$ & \\
\hline Tumour size, mm & $22.8 \pm 13.6(0.1-12)$ & $18.1 \pm 10.6(0.1-70)$ & $30.9 \pm 14.4(0.9-12)$ & $<0.001$ \\
\hline Tumour size distribution & & & & $<0.001$ \\
\hline$<1 \mathrm{~cm}$ & $37(7.3)$ & $36(11.3)$ & $1(0.5)$ & \\
\hline $1-2 \mathrm{~cm}$ & $240(47.6)$ & $196(61.6)$ & $44(23.6)$ & \\
\hline$>2 \mathrm{~cm}$ & $228(45.1)$ & $86(27.1)$ & $142(75.9)$ & \\
\hline Histology & & & & $<0.001$ \\
\hline DCIS & $67(13.3)$ & $53(16.7)$ & $14(7.5)$ & \\
\hline IDC & $386(76.4)$ & $224(70.4)$ & $162(86.6)$ & \\
\hline ILC & $36(7.1)$ & $34(10.7)$ & $2(1.1)$ & \\
\hline Other invasive cancer & $16(3.2)$ & $7(2.2)$ & $9(4.8)$ & \\
\hline Axillary lymph node status & & & & $<0.001$ \\
\hline Negative & $286(56.6)$ & $201(63.2)$ & $85(45.5)$ & \\
\hline Positive & $189(37.4)$ & $87(27.4)$ & $102(54.5)$ & \\
\hline Not examined & $30(5.9)$ & $30(9.4)$ & $0(0)$ & \\
\hline ER status & & & & 0.09 \\
\hline Positive & $375(74.3)$ & $245(77.0)$ & $130(69.5)$ & \\
\hline Negative & $125(24.8)$ & $69(21.7)$ & $56(29.9)$ & \\
\hline Unknown & $5(0.9)$ & $4(1.3)$ & $1(0.6)$ & \\
\hline PR status & & & & $<0.001$ \\
\hline Positive & $330(65.3)$ & $227(71.4)$ & $104(55.7)$ & \\
\hline Negative & $169(33.5)$ & $86(27.0)$ & $82(43.8)$ & \\
\hline Unknown & $6(1.2)$ & $5(1.6)$ & $1(0.5)$ & \\
\hline Grading & & & & $<0.001$ \\
\hline I & $44(8.7)$ & $39(12.3)$ & $5(2.7)$ & \\
\hline II & $301(59.6)$ & $163(51.2)$ & $138(73.8)$ & \\
\hline III & $67(13.3)$ & $56(17.6)$ & $11(5.9)$ & \\
\hline Not determined & $93(18.4)$ & $60(18.9)$ & $33(17.6)$ & \\
\hline Mib-1 & & & & $<0.001$ \\
\hline$\leq 20 \%$ & $306(60.6)$ & $222(69.8)$ & $84(44.9)$ & \\
\hline$>20 \%$ & $199(39.4)$ & $96(30.2)$ & $103(55.1)$ & \\
\hline Her-2 status & & & & $<0.001$ \\
\hline Positive & $138(27.3)$ & $70(22.0)$ & $68(36.4)$ & \\
\hline Negative & $367(72.7)$ & $248(78.0)$ & $119(63.6)$ & \\
\hline Triple-negative cancer & & & & 0.56 \\
\hline Yes & $75(14.8)$ & $45(14.2)$ & $30(16.0)$ & \\
\hline No & $430(85.2)$ & $273(85.8)$ & $157(84)$ & \\
\hline
\end{tabular}

Data are presented as $n(\%)$ or mean \pm SD (range), as appropriate. DCIS, ductal carcinoma in situ; IDC, invasive ductal carcinoma; ILC, invasive lobular carcinoma; ER, oestrogen receptor; PR, progesterone receptor.

bution was significantly different between cohorts; the majority of patients from Italy had tumours measuring from 1 to $2 \mathrm{~cm}(232 / 318,72.9 \%)$, whereas the majority of those from China had tumours measuring $>2 \mathrm{~cm}(142 / 187$, 75.9\%). Histological type distribution was also different between cohorts. While invasive ductal carcinoma was the more represented histotype in both cohorts, ductal carcinoma in situ was found in 16.7 and $7.5 \%$, and invasive lobular carcinoma in 10.7 and $1.1 \%$ in the Italian and Chinese cohorts, respectively. In general, Chinese women had higher rates of invasive carcinoma (92.5 vs. $83.3 \%, p<$ 0.01 ). The proportion of patients having metastatic axillary lymph nodes was $27.4 \%$ in the Italian group and $54.4 \%$ in the Chinese one $(p<0.001)$. Rates of positive oestrogen receptor status did not differ significantly (77.0 vs. $69.5 \%$, $p=0.09$ ), whereas rates of progesterone receptor status did (71.4 vs. $44.7 \%, p<0.001$ ). As for tumour grading, patients in the Chinese cohort had a lower proportion of G1 grade ( 2.7 vs. $12.3 \%$ ). The proportion of patients with Mib-1 > $20 \%$ was $30.2 \%$ in the Italian cohort and $55.1 \%$ in the Chinese cohort $(p<0.001)$. Her-2 positivity was higher among Chinese women ( 36.4 vs. $22 \%, p<0.001$ ), whereas proportions of triple-negative breast cancer did not differ between the two groups ( 14.2 vs. $16 \%, p=0.56$ ). 


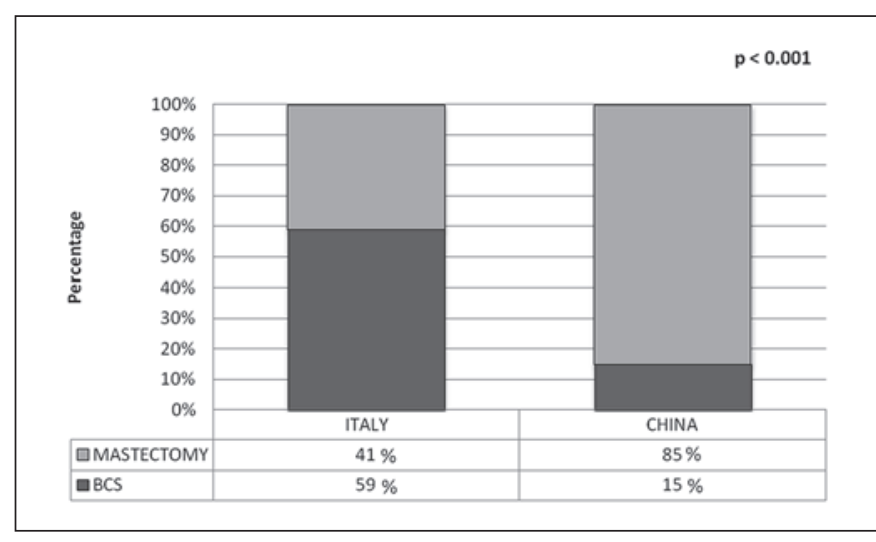

Fig. 1. Type of surgical treatment in the 2 cohorts of patients with breast cancer.

Table 2. Multivariate logistic regression for factors associated with mastectomy for both countries

\begin{tabular}{|c|c|c|c|c|}
\hline Variable & SE & OR & 95\% CI Wald & $p$ value \\
\hline Country & & & & $<0.01^{*}$ \\
\hline China & 0.27 & 4.23 & $2.50-7.14$ & \\
\hline Italy & Reference & & & \\
\hline Age & & & & 0.99 \\
\hline$\leq 40$ years & 0.27 & 1.00 & $0.59-1.71$ & \\
\hline$>40$ years & Reference & & & \\
\hline Histotype & & & & $0.04^{*}$ \\
\hline In situ & 0.33 & 0.39 & $0.21-0.74$ & \\
\hline Invasive & Reference & & & \\
\hline Tumour size & & & & $<0.01^{*}$ \\
\hline$>2 \mathrm{~cm}$ & 0.24 & 0.36 & $0.22-0.59$ & \\
\hline$\leq 2 \mathrm{~cm}$ & Reference & & & \\
\hline Lymph node status & & & & $<0.01^{*}$ \\
\hline Negative & 0.25 & 0.27 & $0.17-0.043$ & \\
\hline Positive & Reference & & & \\
\hline
\end{tabular}

* Statistically significant.

\section{Surgical Treatment}

We evaluated the use of mastectomy and breast conservation as upfront surgery and the use of sentinel node biopsy. In the Italian cohort, 188/318 (59\%) patients underwent breast-conserving surgery and 130/318 (41\%) underwent mastectomy. In the Chinese cohort, 28/187 (15\%) patients received breast-conserving surgery and 159/187 (85\%) received mastectomy (Fig. 1). The difference in surgical treatment was statistically significant $(p<$ $0.001)$. Sentinel node biopsy was carried out in $245 / 318$ (77\%) and 68/187 (33\%) of patients in the Italian and Chinese cohorts, respectively. The difference in the use of sentinel node biopsy was also statistically significant $(p<$ 0.001; Fig. 2). At the Chinese institution, the rates of breast-conserving surgery increased from 15 to $23 \%$ and

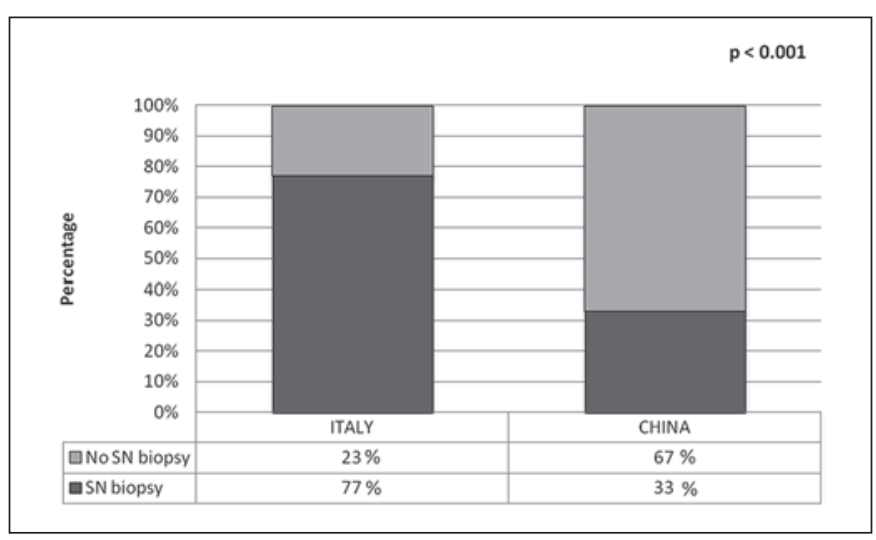

Fig. 2. Sentinel node biopsy in the 2 cohorts of patients with breast cancer.

the usage of sentinel node biopsy increased from 33 to $42 \%$ in the last 2 years (2018-2019).

\section{Factors Associated with Mastectomy as Upfront Surgery}

At multivariate analysis, women were more likely to undergo mastectomy if they belonged to the Chinese cohort, or had tumours larger than $2 \mathrm{~cm}$, invasive disease, or positive axillary lymph nodes (Table 2). We did not find any association between choice of mastectomy as upfront surgery and age younger or older than 40 years. The strongest predictor of receiving mastectomy was belonging to the Chinese cohort (OR 4.23, 95\% CI 2.507.14).

\section{Postoperative Treatment}

In total, 131 patients received adjuvant chemotherapy, 174 (34.5\%) endocrine therapy, 200 (39.6\%) chemotherapy plus endocrine therapy, and 253 (50.01\%) radiotherapy. Chemotherapy alone and chemotherapy followed by endocrine therapy were administrated more frequently in the Chinese group $(p=0.027$ and $p<0.01$, respectively), while endocrine therapy alone and postoperative radiotherapy were administrated more frequently in the Italian group $(p<0.01$ and $p=0.019$, respectively; Table 3).

\section{Survival Analysis}

In the Italian cohort, after a median follow-up of 50.5 months, 39 patients relapsed and 11 died, while in the Chinese one, after a median follow-up of 24 months, 38 patients relapsed and 6 died. In the Chinese cohort most of the patients were lost to follow-up after 36 months from primary treatment, thus survival analysis revealed a 3 -year overall survival rate of 94 and $87 \%$, and a diseasefree survival rate of 91 and $63 \%$ in the Italian and Chinese groups, respectively (Fig. 3). 


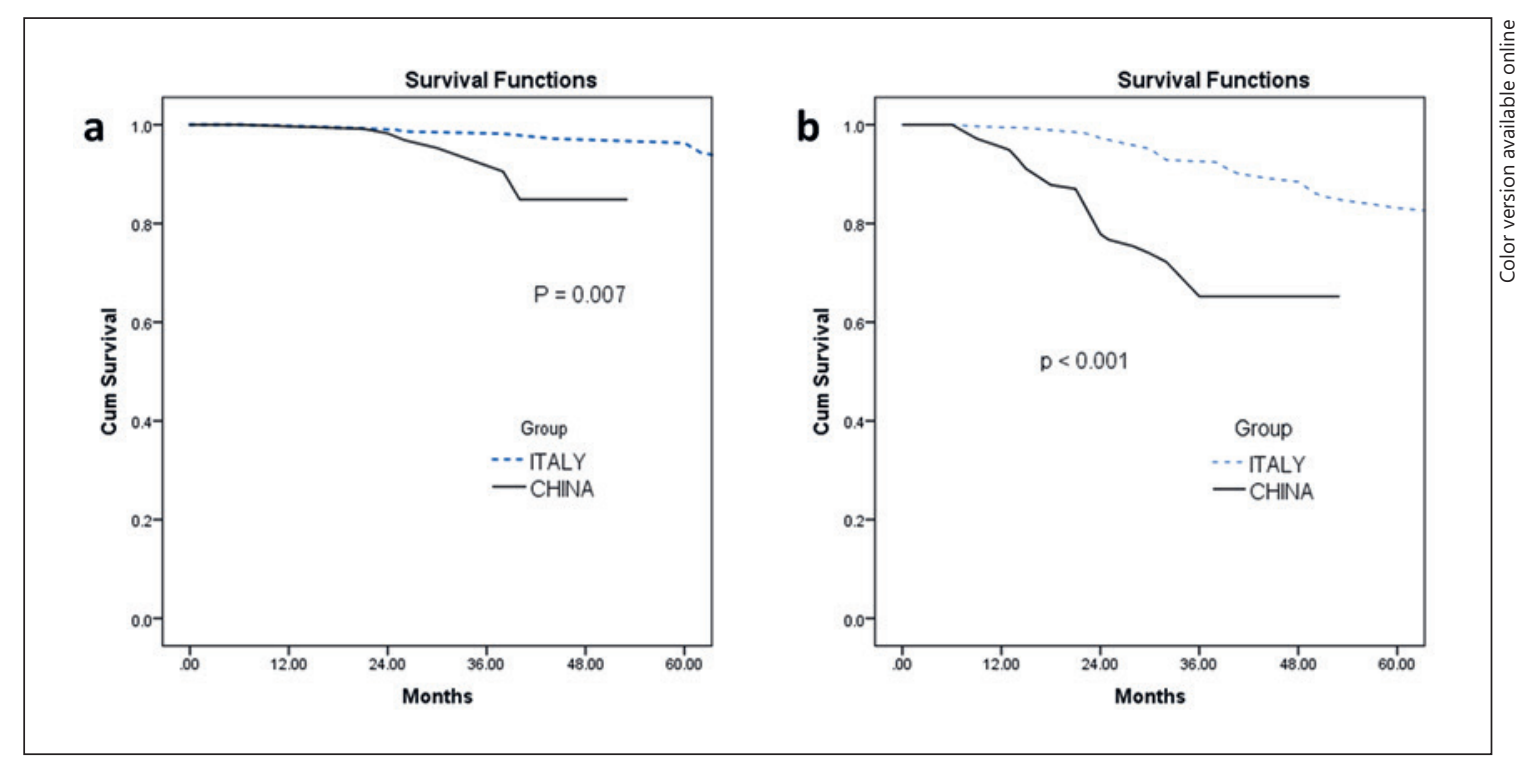

Fig. 3. Overall survival (a) and disease-free survival (b) of the study population.

Table 3. Postoperative treatment in the study population

\begin{tabular}{llrrr}
\hline Treatment & $\begin{array}{l}\text { Total } \\
(n=505)\end{array}$ & $\begin{array}{l}\text { Italy } \\
(n=318)\end{array}$ & $\begin{array}{l}\text { China } \\
(n=187)\end{array}$ & $p$ value \\
\hline Chemotherapy & $131(25.9)$ & $72(22.6)$ & $59(31.3)$ & 0.027 \\
Endocrine therapy & $174(34.5)$ & $153(48.1)$ & $21(11.2)$ & $<0.01$ \\
Chemotherapy + endocrine therapy & $200(39.6)$ & $93(29.3)$ & $107(57.2)$ & $<0.01$ \\
Radiotherapy & $253(50.01)$ & $172(54.1)$ & $81(43.3)$ & 0.019 \\
\hline
\end{tabular}

Data are presented as $n(\%)$.

\section{Discussion}

Breast cancer in premenopausal women represents a challenging health issue, which requires a dedicated multidisciplinary team approach [16-18]. Tumours diagnosed in that group usually have a more aggressive biologic behaviour than those in the older counterpart. Indeed, premenopausal breast cancer is associated with a worse prognosis, which is attributable to less favourable clinicopathologic parameters and to more advanced stage at presentation $[9,17]$. One of the aims of the present study was to ascertain the clinicopathologic features of premenopausal breast cancer in two cohorts of women from Italy and China. We observed that characteristics which generally indicate a more aggressive biological behaviour and a worse clinical prognosis were significantly more represented in the Chinese cohort, such as high proliferative index, Her-2 positivity, and lymph node positivity. These results are consistent with those from studies comparing breast cancer in the USA and China [8]. One reason for these findings could be that certain differences in the genetics of breast cancer may exist between populations from different ethnic groups. However, another possible explanation for this fact in the present study could be that the mean tumour size in the Chinese cohort was larger than that observed in the Italian one (18 vs. 31 $\mathrm{mm}$ ). This suggests that women of the Chinese group are not willing to seek medical attention until they notice a large palpable cancer mass in their breasts. Histological types were different between the two study populations, with the proportion of ductal carcinoma in situ being statistically higher in the Italian cohort (16.7 vs. $7.5 \%)$. Ductal carcinoma in situ differs from invasive cancer in both clinical presentation, as it usually presents as a non-palpable lesion seen on mammogram, and biological behaviour [19]. The above-described variability in tumour features between the two cohorts could also be related to the existing differences in mammographic screening programs, which in Italy first started in the 1990s and are mostly offered to patients aged 50-69 years [20]. The Chinese government launched two national breast cancer screening projects in 2008 , covering 53 cities and $200 \mathrm{ru}-$ 
ral areas. Interestingly, Chinese screening programs target women aged 35-69 years, thus encompassing a larger age range which also includes premenopausal women [21]. As a consequence, in the Chinese cohort of the present study, more premenopausal women should have been expected to have smaller and subclinical tumours compared to the Italian cohort. Instead, we observed the opposite. The main reason probably lies in the participation rates to breast cancer screening programs, which in China are lower than in western countries [22, 23]. In particular, in Italy participation rates are close to $60 \%$, while in Sichuan province (where the city of Leshan is located), they are around 30\% and even less in rural areas [23]. Public education and awareness of early detection of breast cancer are of paramount importance for reducing mortality and improving the quality of life of affected women $[3,24]$.

Yet another aspect of our study was to evaluate surgical management in the Italian and Chinese women. Fifty-nine percent of Italian women received breast conservation as upfront surgery, compared to $15 \%$ in Chinese women. Similarly, in a study on 8,395 premenopausal breast cancer patients from western China, only $11.7 \%$ underwent breast-conserving surgery [9]. Interestingly, the multivariate analysis of our study showed that the strongest predictor of receiving mastectomy was belonging to the Chinese cohort. High rates of mastectomy in the Chinese patients can be to some extent justified by the large tumour size at the time of diagnosis. In fact, in our study two-thirds of Chinese patients had a tumour size $>2 \mathrm{~cm}$, whereas almost two-thirds of Italian patients had tumours $\leq 2 \mathrm{~cm}$. It should be taken into account that surgical treatment of young patients with breast cancer should not differ from their older counterparts $[5,15,25$, 26]. Although young age at the time of diagnosis is an independent risk factor for local recurrence, no difference was found in survival between patients undergoing mastectomy compared with those undergoing breastconserving surgery $[17,27]$. Thus, breast-conserving surgery should be considered the option of choice when an acceptable aesthetic result is preventable, unless in the presence of breast cancer gene mutations $[25,26]$. Breastconserving surgery presents many advantages over mastectomy, such as psychological impact, shorter hospital stay, and shorter time to work return $[25,26]$. However, breast conservation can be carried out only when adjuvant radiotherapy is warranted. This cannot be easy for patients coming from some Chinese rural areas. It is known that neo-adjuvant chemotherapy can be performed to down-stage breast cancer and convert from mastectomy to breast conservation in selected cases. However, in the present study, patients undergoing preoperative chemotherapy belonged only to the Italian cohort.
We found that the use of sentinel node biopsy was different among the two countries. Again, this finding is similar to that observed in studies comparing US and Chinese breast cancer cohorts [8]. Sparing lymph node dissection is of paramount importance in modern breast practice, especially among young women. In effect, no women with breast cancer should receive axillary dissection when lymph nodes are not metastatic [28]. In our study, Italian women were more likely to undergo sentinel node biopsy. Looking at the percentages of sentinel node biopsy carried out in the Chinese population (33.0\%), and considering the rates of non-metastatic axillary lymph nodes (45.5\%), one can argue that a more extensive use of sentinel node biopsy would have been of benefit for some patients.

In this study, the survival analysis was limited because most of the patients in the Chinese study population were lost at follow-up after 36 months from the primary treatment. With this limitation, we observed that both overall survival and disease-free survival rates were significantly higher in the Italian population. The reasons for those findings may be explained taking into consideration the differences in disease stage at diagnosis. Tumour size was significantly larger in the Chinese cohort (30.9 vs. 18.1 $\mathrm{mm}$ ), as well as the rate of lymph node metastatic involvement (54.5 vs. $27.4 \%$ ). Tumour size and lymph node status still remain the most important prognostic factors in breast cancer [28-30]. In addition, Her-2-positive tumours and tumour proliferative index $>20 \%$ were observed more frequently among Chinese women. The latter features can also be included among factors influencing differences in survival outcomes. Adjuvant chemotherapy was administrated more frequently in the Chinese group. Interestingly, $43.3 \%$ of Chinese women were submitted to radiotherapy, in spite of the fact that only $15 \%$ received breast-conserving surgery. This implies that many of them received radiation for locally advanced tumours.

Of note, after the exchange program, Chinese surgeons were more prone to propose less invasive surgery for breast cancer to their patients. In fact, the rates of breast-conserving surgery increased from 15\% in 2012 2016 to $23 \%$ in $2018-2019$, and the usage of sentinel node biopsy from 33 to $42 \%$. This progressive shift towards more conservative treatment was also due to the experience seen during the exchange program, and to the stable relationship created since then. Indeed, some of the clinical cases of the two institutions have been shared via web conference and some of the most complex cases from the Chinese institution have been discussed during the multisciplinary meeting at the Italian breast unit, where a motivated opinion on management was taken and communicated. Surgical management of breast cancer is an evolving topic, in which cultural issues and national 
health systems play a visibly major role. We believe that information on the diversities of breast cancer features and its clinical management is essential for planning health measures, especially in the current era of globalization. It should be advisable that all patients with cancer would receive standard treatments aiming to improve oncological outcomes and quality of life. As physicians, our effort to try to diminish health care disparities should include use of evidence-based strategies, information, and data sharing for epidemiological studies. International medical exchange programs can be useful for establishing and maintaining relationships between health care professionals.

This study has some limitations, the main one being the relatively small sample size in both cohorts, thus it cannot be considered entirely representative of the situation of the Italian and Chinese populations. However, our results are consistent with other studies addressing the topic of differences in breast cancer between China and the USA. In addition, in this study data regarding longterm oncological outcomes are lacking. However, it was designed primarily to ascertain differences in clinicopathologic characteristics and surgical treatment. Despite the stated limitations, the present study has some points of strengths: to our knowledge it represents one of the few studies reporting on diversity in breast cancer characteristics and management between China and European countries. Furthermore, it highlights the importance of sharing information and experiences in the management of breast cancer between countries with different social and health care systems.

\section{Conclusions}

Our results show that tumour features and surgical strategies for patients with premenopausal breast cancer may differ significantly between Italy and China. As a general trend, since the international exchange program, patients from the Chinese institution have been offered more frequently breast conservation and sentinel node biopsy. International exchange programs can help in de- signing epidemiological studies that may be useful for strategies aiming to improve breast cancer prevention and control.

\section{Acknowledgements}

We would like to thank all the health professionals of the two institutions who are involved in the management of breast cancer patients.

\section{Statement of Ethics}

This study was conducted in compliance with the Declaration of Helsinki in its revised version of 1975 and its amendments of 1983, 1989, and 1996, and was approved by the Ethics Committees of the two institutions involved. Due to the retrospective observational nature of the study, patient consent was deemed not necessary.

\section{Disclosure Statement}

None of the authors have any conflicts of interest in relation to this submission.

\section{Funding Sources}

This research was funded from the "Fondazione di Sardegna" (project grant 2017.1870). This institution gave financial support for the publication work involving the international cooperation of the two institutions.

\section{Author Contributions}

A.F. and X.Y.Z.: study design and data interpretation, and writing of the manuscript. A.F. and V.S.: statistical analysis and interpretation of oncological outcomes. P.C., C.T., and G.C.G.: collection of surgical data and interpretation of the results (Italian cohort). Y.P.L., Q.Z., Y.Y.Z., Y.M.L., and S.Q.D.: collection of data and interpretation of the results (Chinese cohort). A.P.: interpretation of data and general supervision of the study. All authors read and approved the final version.

\section{References}

1 Pineda MD, White E, Kristal AR, Taylor V. Asian breast cancer survival in the US: a comparison between Asian immigrants, US-born Asian Americans and Caucasians. Int J Epidemiol. 2001 Oct;30(5):976-82.

2 Yap YS, Singh AP, Lim JH, Ahn JH, Jung KH, Kim J, et al. Elucidating therapeutic molecular targets in premenopausal Asian women with recurrent breast cancers. NPJ Breast Cancer. 2018 Jul;4(1):19.
3 Wang YC, Wei LJ, Liu JT, Li SX, Wang QS. Comparison of Cancer Incidence between China and the USA. Cancer Biol Med. 2012 Jun;9(2):128-32.

4 http://globocan.iarc.fr/Default.aspx (Ferlay J, 2013).

5 Ghoncheh M, Pournamdar Z, Salehiniya H. Incidence and Mortality and Epidemiology of Breast Cancer in the World. Asian Pac J Cancer Prev. 2016;17(S3):43-6.
6 Williams J, Garvican L, Tosteson AN, Goodman DC, Onega T. Breast cancer screening in England and the United States: a comparison of provision and utilisation. Int $\mathrm{J}$ Public Health. 2015 Dec;60(8):881-90.

7 Son BH, Dominici LS, Aydogan F, Shulman LN, Ahn SH, Cho JY, et al. Young women with breast cancer in the United States and South Korea: comparison of demographics, pathology and management. Asian Pac J Cancer Prev. 2015;16(6):2531-5. 
8 Sivasubramaniam PG, Zhang BL, Zhang Q, Smith JS, Zhang B, Tang ZH, et al. Breast Cancer Disparities: A Multicenter Comparison of Tumor Diagnosis, Characteristics, and Surgical Treatment in China and the U.S. Oncologist. 2015 Sep;20(9):1044-50.

9 Feng F, Wei Y, Zheng K, Li Y, Zhang L, Wang $\mathrm{T}$, et al. Comparison of epidemiological features, clinicopathological features, and treatments between premenopausal and postmenopausal female breast cancer patients in western China: a retrospective multicenter study of 15,389 female patients. Cancer Med. 2018 Jun;7(6):2753-63.

10 Li ZS, Yao L, Liu YQ, Ouyang T, Li JF, Wang TF, et al. Breast cancer subtypes and survival in chinese women with operable primary breast cancer. Chin J Cancer Res. 2011 Jun; 23(2):134-9.

11 Zeng H, Zheng R, Zhang S, Zou X, Chen W. Female breast cancer statistics of 2010 in China: estimates based on data from 145 population-based cancer registries. J Thorac Dis. 2014 May;6(5):466-70.

12 Rossi S, Crocetti E, Capocaccia R, Gatta G, Buzzoni C, Giacomin A, et al.; AIRTUM Working Group. Estimates of cancer burden in Italy. Tumori. 2013 May-Jun;99(3):416-24.

13 Ghiasvand R, Adami HO, Harirchi I, Akrami R, Zendehdel K. Higher incidence of premenopausal breast cancer in less developed countries; myth or truth? BMC Cancer. 2014 May; 14(1):343.

14 Chen C, Sun S, Yuan JP, Wang YH, Cao TZ, Zheng HM, et al. Characteristics of breast cancer in Central China, literature review and comparison with USA. Breast. 2016 Dec;30: 208-13.

15 Cardoso F, Loibl S, Pagani O, Graziottin A, Panizza P, Martincich L, et al.; European Society of Breast Cancer Specialists. The European Society of Breast Cancer Specialists rec- ommendations for the management of young women with breast cancer. Eur J Cancer. 2012 Dec;48(18):3355-77.

16 Fancellu A, Soro D, Castiglia P, Marras V, Melis M, Cottu P, et al. Usefulness of magnetic resonance in patients with invasive cancer eligible for breast conservation: a comparative study. Clin Breast Cancer. 2014 Apr; 14(2):114-21.

17 Suter MB, Pagani O. Should age impact breast cancer management in young women? Fine tuning of treatment guidelines. Ther Adv Med Oncol. 2018 Jun;10:1758835918776923.

18 Hung MC, Ekwueme DU, Rim SH, White A. Racial/ethnicity disparities in invasive breast cancer among younger and older women: an analysis using multiple measures of population health. Cancer Epidemiol. 2016 Dec;45: 112-8.

19 Fancellu A, Turner RM, Dixon JM, Pinna A, Cottu P, Houssami N. Meta-analysis of the effect of preoperative breast MRI on the surgical management of ductal carcinoma in situ. Br J Surg. 2015 Jul;102(8):883-93.

20 Fancellu A, Sanna V, Sedda ML, Delrio D, Cottu P, Spanu A, et al. Benefits of Organized Mammographic Screening Programs in Women Aged 50 to 69 years: A Surgical Perspective. Clin Breast Cancer. 2019 Oct; 19(5):e637-42.

21 Huang Y, Zhou K, Li H, Wang A, Li J, Pang Y, et al. Knowledge, attitudes, and behaviour regarding breast cancer screening among women from different socio-economic regions in southwest China: a cross-sectional study. Asian Pac J Cancer Prev. 2011;12(1):203-9.

22 Fan L, Strasser-Weippl K, Li JJ, St Louis J, Finkelstein DM, Yu KD, et al. Breast cancer in China. Lancet Oncol. 2014 Jun;15(7):e27989.

23 Wu Z, Liu Y, Li X, Song B, Ni C, Lin F. Factors associated with breast cancer screening par- ticipation among women in mainland China: a systematic review. BMJ Open. 2019 Aug 26; 9(8):e028705.

24 Ghoncheh M, Momenimovahed Z, Salehiniya $H$. Epidemiology, Incidence and Mortality of Breast Cancer in Asia. Asian Pac J Cancer Prev. 2016;17(sup3 S3):47-52.

25 Fancellu A, Sanna V, Cottu P, Feo CF, Scanu AM, Farina $G$, et al. Mastectomy patterns, but not rates, are changing in the treatment of early breast cancer. Experience of a single European institution on 2315 consecutive patients. Breast. 2018 Jun;39:1-7.

26 Fancellu A. Considerations arising from requests from patients for a bilateral mastectomy who are eligible for breast-conserving surgery: factors weighing for and against performing the operation. Oncol Lett. $2016 \mathrm{Jul}$; 12(1):764-6.

27 Vila J, Gandini S, Gentilini O. Overall survival according to type of surgery in young $(\leq 40$ years) early breast cancer patients: A systematic meta-analysis comparing breast-conserving surgery versus mastectomy. Breast. 2015 Jun;24(3):175-81.

28 Fancellu A, Cottu P, Feo CF, Bertulu D, Giuliani G, Mulas S, et al. Sentinel node biopsy in early breast cancer: lessons learned from more than 1000 cases at a single institution. Tumori. 2012 Jul-Aug;98(4):413-20.

29 Huang TW, Kuo KN, Chen KH, Chen C, Hou WH, Lee WH, et al. Recommendation for axillary lymph node dissection in women with early breast cancer and sentinel node metastasis: A systematic review and meta-analysis of randomized controlled trials using the GRADE system. Int J Surg. 2016 Oct;34:7380.

30 Güler EN. Gene Expression Profiling in Breast Cancer and Its Effect on Therapy Selection in Early-Stage Breast Cancer. Eur J Breast Health. 2017 Oct;13(4):168-74. 